\title{
Changing Prevalence of Asthma and Allergic Diseases among Kuwaiti Children
}

\author{
An ISAAC Study (Phase III)
}

\section{A. Owayed ${ }^{\text {a }} \quad$ N. Behbehani ${ }^{\text {b }} \quad$ J. Al-Momen ${ }^{c}$}

Departments of a Pediatrics and ${ }^{b}$ Medicine, Kuwait University, and ${ }^{c}$ Department of Pediatrics, Amiri Hospital, Kuwait

\section{Key Words \\ Asthma $\cdot$ Epidemiology $\cdot$ Allergic rhinitis $\cdot$ Eczema}

\begin{abstract}
Objectives: To estimate the prevalence of asthma and allergic diseases in 13- and 14-year-old schoolchildren and to compare it with previous phase I data. Subjects and Methods: A survey of 2,922 third and fourth grade students from randomly selected intermediate level schools across Kuwait was conducted. Supervised, self-administered, written and video questionnaires of the International Study of Asthma and Allergies in Childhood (ISAAC) was used. Results: Of the 2,922 students, 2,882 (96.3\%) completed the questionnaires. The prevalence $(95 \% \mathrm{Cl})$ in the written questionnaire for wheeze ever, current wheeze (within the last 12 months) and physician diagnosis of asthma were 13.4, 7.6 and $15.6 \%$, respectively. The prevalence $(95 \% \mathrm{Cl})$ for symptoms of allergic rhinitis (AR) ever, current symptoms of $A R$, and diagnosis of AR was $41.4,27.6$ and $22.2 \%$, respectively. The prevalence $(95 \% \mathrm{Cl})$ for itchy rash ever, current itchy rash, and diagnosis of eczema was $10.6,8.3$ and $12.8 \%$, respectively. Comparing to ISAAC phase I data (1995-1996), the prevalence of current wheeze has decreased from 16.1 to $7.6 \%(p<0.001)$. Current symptoms of AR decreased from 30.7 to $27.6(p=0.008)$ and current itchy rash decreased from 17.5 to $10.6 \%(p<0.001)$. However, physician diagnoses of asthma and eczema re-
\end{abstract}

mained the same as in the previous study, but physician diagnosis of AR increased from 17.1 to $22.2 \%$ ( $p<0.001)$. Conclusion: The findings show that there is a decrease in the self-reported symptoms of allergic diseases over a 5-year period while physician diagnoses of these diseases remained the same over the same period.

Copyright $\odot 2008$ S. Karger AG, Basel

\section{Introduction}

There is an international variation in the prevalence of asthma and allergic diseases. Although there is considerable concern over the increase in prevalence of asthma and allergic diseases in childhood over the last decade [1], it is not clear whether or not this increase still exists. The International Study of Asthma and Allergies in Childhood (ISAAC) has established a standardized methodology to compare prevalence and severity of asthma and atopic diseases in children both within and between countries. The phase I study of the prevalence of asthma and allergic diseases was done in 1995-1996 [2, 3]. Since then no other study has been done. Hence we studied the prevalence of asthma and allergic diseases among children aged 13 and 14 years in 2001-2002 using the ISAAC phase III protocol and compared the findings with those of the previous study.

Dr. Abdullah Owayed

Department of Pediatrics, Kuwait University

PO Box 24923

13110 Safat (Kuwait)

Tel. +965 533 8940, Fax +965 531 9486, E-Mail owayedaf@hsc.edu.kw 
Table 1. Percent responses to the key questions of the written questionnaire

\begin{tabular}{|c|c|c|c|c|c|c|c|}
\hline & \multicolumn{2}{|c|}{ Boys $(n=1,423)$} & \multicolumn{2}{|c|}{ Girls $(\mathrm{n}=1,459)$} & \multicolumn{2}{|c|}{ Total $(\mathrm{n}=2,882)$} & \multirow[t]{2}{*}{$\mathrm{p}$ value } \\
\hline & $\%$ & $95 \% \mathrm{CI}$ & $\%$ & $95 \% \mathrm{CI}$ & $\%$ & $95 \% \mathrm{CI}$ & \\
\hline Wheeze ever & 15.2 & $13.4-17.1$ & 11.7 & $10.1-13.3$ & 13.4 & $12.2-14.6$ & 0.001 \\
\hline Wheeze in the last 12 months & 9.3 & $8.1-11.1$ & 5.9 & $4.7-7.1$ & 7.6 & $6.6-8.6$ & 0.001 \\
\hline Severe wheeze in the last year & 5.5 & $4.3-6.7$ & 2.9 & $2-3.8$ & 4.2 & $3.5-4.9$ & 0.001 \\
\hline Diagnosis of asthma & 19.6 & $17.5-21.7$ & 11.6 & $10-13.2$ & 15.6 & $14.3-16.9$ & 0.001 \\
\hline Exercise-induced wheeze in the last year & 16.4 & $14.5-18.3$ & 11.7 & $10.1-13.3$ & 14 & $12.7-15.3$ & 0.001 \\
\hline Nocturnal cough in the last year & 37.9 & $35.4-40.4$ & 30.6 & $28.2-34$ & 34.2 & $32.5-35.9$ & $<0.001$ \\
\hline Symptoms of rhinitis ever & 46.1 & $43.5-48.7$ & 37 & $34.5-39.5$ & 41.4 & $39.6-43.2$ & $<0.001$ \\
\hline Symptoms of rhinitis in the last year & 31.1 & $28.7-33.5$ & 24.1 & $21.9-26.3$ & 27.6 & $26-29.2$ & $<0.001$ \\
\hline Itchy and red eye in the last year & 14.8 & $13-16.6$ & 10.4 & $8.8-12$ & 12.6 & $11.4-13.8$ & 0.001 \\
\hline Diagnosis of allergic rhinitis & 23.9 & $21.7-26.1$ & 20.6 & $18.5-22.7$ & 22.2 & $20.7-23.7$ & 0.043 \\
\hline Itchy rash ever & 10.9 & $9.3-12.5$ & 10.3 & $8.7-11.9$ & 10.6 & $9.5-11.7$ & 0.614 \\
\hline Itchy rash in the last year & 8.6 & $7.1-10.1$ & 8 & $6.6-9.4$ & 8.3 & $7.3-9.3$ & 0.828 \\
\hline Diagnosis of eczema & 11.7 & $10-13.4$ & 13.8 & $12-15.6$ & 12.8 & $11.6-14$ & 0.122 \\
\hline
\end{tabular}

p value for male vs. female.

\section{Subjects and Methods}

\section{Sampling Methods}

Schoolchildren aged 13 and 14 years were targeted for the study using the ISAAC protocol. A list of intermediate level schools from each of the five governorates in Kuwait was obtained from the Department of Education. Eight schools, four for boys and four for girls, from each governorate were selected using random table. The third and fourth grades were included in the study as they contain the majority of children aged 13-14 years. Approvals to conduct the survey were obtained from appropriate authorities in the Ministry of Health and Ministry of Education. The study was carried out in 2001-2002.

\section{Questionnaires}

The ISAAC written and video questionnaires were used. Phase III written questionnaire is a repetition of phase I. It included questions on past and current wheezing episodes, wheezing frequency, sleep disturbance, speech limitation during attacks, exercise-induced wheezing and persistent cough unrelated to respiratory infections. Other questionnaires focused on the presence and severity of rhinitis and atopic eczema. The video questionnaires comprised five areas related to asthma symptoms and severity, including: moderate wheezing at rest, wheezing and shortness of breath after exercise, nocturnal wheezing, nocturnal cough, and severe wheezing and shortness of breath at rest. To avoid potential bias, the written questionnaires were completed before the video questionnaires.

\section{Statistical Analysis}

The data were entered into a computer according to the ISAAC Committee instructions. A second person rechecked $20 \%$ of the data entries from each school. The data were analyzed using SPSS software version 12 . The prevalence of each symptom was calculated with $95 \%$ CI. A comparison between the frequency of symptoms was made using $\chi^{2}$ test, and $\mathrm{p}$ value $<0.05$ was considered significant.

\section{Results}

Of the 2,922 Kuwaiti students, 2,882(96.3\%) completed the questionnaires. Missing data for the key questions, e.g. presence of symptoms ever or physician diagnosis of any of the conditions ranged from $3.9 \%$ for wheeze ever to $14.6 \%$ for physician's diagnosis of eczema. The responses to the written questionnaire, based on gender, are given in table 1 . The overall prevalence rates (95\% CI) for wheeze ever, wheeze within the last year, and physician diagnosis of asthma were 13.4\% (12.2-14.6), 7.6\% (6.6-8.6), and 15.6\% (14.3-16.9), respectively. The prevalence rates for symptoms of asthma and that included asthma were greater in boys than girls and the differences was statistically significant $(p=0.001)$. The most significant differences in wheeze ever, wheeze in the last 12 months, severe wheeze in the last year, diagnosis of asthma, exercise-induced wheezing in the last year, and nocturnal cough in the last year were greater in boys than girls and the differences were statistically significant $(\mathrm{p}=$ 0.001).

Rhinitis was the most common allergic disease affecting both boys and girls. The overall prevalence rates $(95 \%$ CI) for symptoms of allergic rhinitis (AR) ever within the last year and physician diagnosis were $41.4 \%$ (39.6-43.2), $27.6 \%$ (26-29.2) and 22.2\% (20.7-23.7), respectively. Also boys had higher prevalence rates than girls for symptoms of AR ever within the last year and the differences were statistically significant $(\mathrm{p}<0.001)$. 
Table 2. Responses to the video questionnaire

\begin{tabular}{|c|c|c|c|c|c|c|c|}
\hline & \multicolumn{2}{|c|}{ Boys $(\mathrm{n}=1,423)$} & \multicolumn{2}{|c|}{ Girls $(\mathrm{n}=1,459)$} & \multicolumn{2}{|c|}{ Total $(\mathrm{n}=2,882)$} & \multirow[t]{2}{*}{$\mathrm{p}$ value } \\
\hline & $\%$ & $95 \%$ CI & $\%$ & $95 \% \mathrm{CI}$ & $\%$ & $95 \% \mathrm{CI}$ & \\
\hline Combined wheezing ever by video & 35.6 & $33.1-38.1$ & 20.5 & $18.4-22.6$ & 27.6 & $25.9-29.2$ & $<0.001$ \\
\hline Combined wheezing in the last year & 24.3 & $22.7-25.9$ & 12.6 & $10.9-14.3$ & 18.4 & $17-19.8$ & $<0.001$ \\
\hline Wheeze at rest ever & 18.1 & $16.1-20.1$ & 10.3 & $8.7-11.9$ & 13.9 & $12.6-14.2$ & $<0.001$ \\
\hline Wheeze at rest in the last year & 11.4 & $9.7-13.1$ & 5.6 & $4.4-6.85$ & 8.4 & $7.4-9.4$ & $<0.001$ \\
\hline Wheeze at rest $\geq 1$ per month & 9.4 & 7.9-10.9 & 4.4 & $3.3-5.5$ & 6.8 & $5.9-7.7$ & $<0.001$ \\
\hline Wheeze during exercise ever & 27.6 & $25.3-29.9$ & 13.5 & $11.7-15.3$ & 20.1 & $18.6-21.6$ & $<0.001$ \\
\hline Wheeze during exercise in the last year & 18.5 & $16.5-20.5$ & 9 & $7.5-10.5$ & 13.7 & $12.4-15$ & $<0.001$ \\
\hline Wheeze during exercise $\geq 1$ per month & 15.8 & $13.9-17.7$ & 7.1 & $5.8-8.4$ & 11.4 & $10.2-12.6$ & $<0.001$ \\
\hline Nocturnal wheeze ever & 12.1 & $10.4-13.8$ & 4.7 & $3.6-5.8$ & 8.2 & $7.2-9.2$ & $<0.001$ \\
\hline Nocturnal wheeze in the last year & 7.1 & $5.8-8.4$ & 2.4 & $1.6-3.2$ & 4.7 & $3.9-5.5$ & $<0.001$ \\
\hline Nocturnal wheeze $\geq 1$ per month & 6.4 & $5.1-7.7$ & 1.9 & $1.2-2.6$ & 4.1 & $3.4-4.8$ & $<0.001$ \\
\hline Nocturnal cough ever & 22.9 & $20.7-25.1$ & 28.4 & $26.1-30.7$ & 25.8 & $23.9-27.7$ & 0.001 \\
\hline Nocturnal cough in the last year & 14.1 & $12.3-15.9$ & 17.5 & $15.6-19.4$ & 15.8 & $14.5-17.1$ & 0.010 \\
\hline Nocturnal cough $\geq 1$ per month & 12.4 & $10.7-14.1$ & 13.8 & $12-15.6$ & 13.1 & $11.9-14.3$ & 0.289 \\
\hline Severe asthma attack ever & 10.7 & $9.1-12.3$ & 5.8 & $4.6-7$ & 8.1 & $7.1-9.1$ & $<0.001$ \\
\hline Severe asthma attack in the last year & 7 & $5.7-8.3$ & 3.4 & $2.5-3.4$ & 5.2 & $4.4-6$ & $<0.001$ \\
\hline Severe asthma attack $\geq 1$ per month & 6.1 & $4.8-7.4$ & 3.2 & $2.3-4.1$ & 4.6 & $3.8-5.4$ & $<0.001$ \\
\hline
\end{tabular}

'Combined' is defined as a positive response to any of the first three wheeze sequences in the video questionnaire (wheeze at rest, wheeze during exercise, or nocturnal wheeze). p value for male vs. female.

The overall prevalence rates for itchy rash ever, rash within the last year and physician diagnosis of eczema were $10.6 \%$ (9.5-11.7), 8.3\% (7.3-9.3) and 12.8\% (11.6-14), respectively. There was no statistically significant difference between boys and girls ( $\mathrm{p} \geq 0.122$ ).

For responses to video questionnaires (table 2), boys also had higher prevalence rates than girls for wheeze at rest, exercise-induced wheeze, and nocturnal wheeze $(\mathrm{p}<0.001)$. However, nocturnal cough ever was more commonly reported by girls than boys ( $\mathrm{p} \leq 0.001$ ).

When the current data were compared to ISAAC phase I data (table 3), the prevalence rates for wheeze ever and current wheeze in the past year decreased from 25.9 to $13.4 \%(\mathrm{p}<0.001)$ and from 16.1 to $7.6 \%$ ( $\mathrm{p}<0.001)$, respectively. The prevalence rates for exercise-induced wheeze in the past year and nocturnal cough decreased from 22.4 to $14.0 \%(\mathrm{p}<0.001)$ and from 38.4 to $34.2 \%$, respectively $(\mathrm{p}=0.001)$. The reduction in the prevalence was observed for both boys and girls as exemplified in the prevalence of current wheeze: from 18 to $9 \%$ for boys and 14.3 to $5.9 \%$ for girls. Similar reductions were observed among both boys and girls in exercise-induced and severe wheeze. Despite a significant decrease in the self-reported symptoms of asthma, the rate of physician diagnosis of asthma remained basically the same $(\mathrm{p}=0.196)$.
Equally the prevalence rates for current symptoms of AR in the current study compared to phase I decreased from 30.7 to $27.6 \%$ ( $\mathrm{p}=0.008)$, itchy rash ever and current itchy rash from 17.5 to $10.6 \%$ and from 12.6 to $8.3 \%$, respectively $(p<0.001)$. However, the rate of physician diagnosis of AR increased from 17.1 to $22.2 \%(\mathrm{p}=0.001)$, but no statistically significant change occurred in the rate of physician diagnosis of eczema $(\mathrm{p}=0.101)$.

\section{Discussion}

The ISAAC phase III study provides for the first time the trend in the prevalence rates of asthma and allergic disease in children in Kuwait. It uses core questionnaires to assess the prevalence and severity of asthma and allergic diseases in a defined population. The validity and repeatability of the ISAAC questionnaires used in this study had been reported in relation to bronchial hyperreactivity [4] and physician-diagnosed asthma [5].

Our data show that the prevalence rates of asthma and respiratory symptoms were higher in boys than girls (table 1) as reported in the previous ISAAC phase I survey [3], thereby indicating that the gender difference is a consistent finding and also similar to findings reported in 
Table 3. Prevalence (\%) of asthma and allergic disease in schoolchildren in Kuwait in 1995-1996 (phase I) and 2001-2002 (current study)

\begin{tabular}{|c|c|c|c|c|c|}
\hline & \multicolumn{2}{|c|}{$1995-1996(n=3,110)$} & \multicolumn{2}{|c|}{$2001-2002(\mathrm{n}=2,822)$} & \multirow[t]{2}{*}{$\mathrm{p}$ value } \\
\hline & $\%$ & $95 \% \mathrm{CI}$ & $\%$ & $95 \% \mathrm{CI}$ & \\
\hline Wheeze ever & 25.9 & $24.5-27.4$ & 13.4 & $12.2-14.4$ & $<0.001$ \\
\hline Current wheeze in past year & 16.1 & $15.8-17.4$ & 7.6 & $6.6-8.6$ & $<0.001$ \\
\hline Diagnosis of asthma & 16.8 & $15.5-18.1$ & 15.6 & $14.3-16.9$ & 0.196 \\
\hline AR ever & 43.9 & $42.2-45.6$ & 41.4 & $39.6-43.2$ & 0.06 \\
\hline Current AR in past year & 30.7 & $29.1-32.4$ & 27.6 & $26-29.2$ & 0.008 \\
\hline Diagnosis of AR & 17.1 & $14.8-18.4$ & 22.2 & $20.7-23.7$ & $<0.001$ \\
\hline Itchy rash ever & 17.5 & $16.2-18.8$ & 10.6 & $9.5-11.7$ & $<0.001$ \\
\hline Current itchy rash & 12.6 & $11.4-13.8$ & 8.3 & $7.3-9.3$ & $<0.001$ \\
\hline Diagnosis of eczema & 11.3 & $10.2-12.4$ & 12.8 & $11.6-14$ & 0.101 \\
\hline Exercise-induced wheeze in the past year & 22.4 & $20.9-23.9$ & 14.0 & $12.7-15.3$ & $<0.001$ \\
\hline Nocturnal cough in the past year & 38.4 & $36.7-40.1$ & 34.2 & $32.5-35.9$ & 0.001 \\
\hline Itchy red eye in the past year & 16.2 & $14.9-17.5$ & 12.6 & $11.4-13.8$ & $<0.001$ \\
\hline
\end{tabular}

$\mathrm{p}$ value for trends.

other countries: Hong Kong [6], United Kingdom [7], and New Zealand [8]. The study in New Zealand showed that the higher prevalence of asthma in boys aged 13 years was partly due to a higher rate of sensitization to indoor allergens as assessed by skin prick test. Because we did not perform sensitization assessment, it is difficult to attribute the gender difference in Kuwait's population to indoor allergens. However, the difference in symptoms like exercise-induced asthma could be due to difference in lifestyle as boys tend to exercise more than girls in $\mathrm{Ku}$ wait. Previous studies in Kuwait showed a very high prevalence of allergic sensitization to airborne allergens among blood donors and asthmatic patients [9-11]. The atopic asthmatics were sensitized to pollens from local trees and plants, namely, prosopis (Mesquite) tree, Chenopodium album (saltbush), and Bermuda grass. It is generally believed that this high prevalence of sensitization is mainly due to plantation and cultivation process of foreign trees to the urban area of Kuwait [11-13]. In contrast to our study, significantly higher rates of asthma symptoms were found in girls in Israel, the United Kingdom, Australia and Germany [14, 15].

When the current study is compared to the previous one (1995-1996) [3], a demonstrable trend toward lower prevalence was observed (table 3). The observed decrease in trend could not be attributed to artifact because: (a) A similar ISAAC protocol was used for both surveys. The study population in both studies consisted of 13- to 14year-old children living in Kuwait and both studies had similarly high response rates. (b) The change in symptoms of the three disease entities we assessed were less susceptible to change in diagnostic behaviors of health care providers. (c) A similar trend in the decrease of prevalence rates was observed for both boys and girls.

It is somewhat surprising that the physician diagnosis of allergic diseases remained the same. This could be due to underreporting of symptoms by the students or overdiagnosis by physicians in phase III survey. Overdiagnosis by the physician may be a result of a worldwide health professional targeted education regarding allergic diseases in general and asthma in particular. This highlights the importance of doing a similar study experimentally using spirometry and skin prick test or allergen-specific IgE to complement the written questionnaire.

A probable explanation for the decrease in symptoms is a period effect in which a decrease in exposure to environmental factors results in a decrease in the risk to susceptible subjects. During the first Gulf war more than 750 oil wells were set on fire in Kuwait by the fleeing Iraqi army. Significant air pollution occurred in Kuwait and surrounding countries $[16,17]$. Some of the people who were exposed to the pollution from these oil fires were reported to have had respiratory symptoms [18]; however, the long-term health effects of these oil fires remain controversial [19]. The reported respiratory symptoms could partially explain the higher symptoms during the first survey, which was done in 1995, compared to the second survey in 2002. Decrease in allergen exposure could be 
the other probable reason. Epidemiological studies have shown that a twofold reduction in allergen exposure at community level would significantly reduce rates of sensitization in early childhood [20], halve the risk of asthma in sensitized children [21] and similarly reduce its severity [22].

In contrast to our study, a trend towards an increase in asthma and asthma-related symptoms has been observed in other countries: Israel [14], England, Wales and Scotland [24-27], USA [28], Australia [29], New Zealand [30]. However, signs indicating a halt in the rising trend in asthma prevalence have been observed in recent studies [31-35]. Possible explanations for the changing prevalence of asthma symptoms include changes in environmental influences such as indoor environmental factors, outdoor air pollution, infections burden in early childhood and duration of breast-feeding. The worldwide results of ISAAC phase III trial showed mixed changes in the trend of prevalence of allergic diseases among the 106 centers in 56 countries; however, there were more decreases in the prevalence of asthma symptoms in the 13- to 14-year age group at high prevalence [36]. Our results show an example of a decrease in most symptoms of allergic diseases, especially asthma.

Our investigation, like others [32-34], did not allow a study of changing trends by specific risk factors. It is possible that a combination of various factors such as nutrition, microbial exposures, early life infections, housing conditions, exposure to outdoor pollutants, allergen exposure and others, may have affected the temporal trend [37-39].

In conclusion, this study shows a trend in the decrease of prevalence rates of asthma and allergic diseases in a nationwide sample of 13- to 14 -year-old schoolchildren in Kuwait.

\section{Acknowledgment}

Skillful secretarial assistance of Mrs. Bena Pereira is duly acknowledged.

\section{References}

1 Woolcock AJ, Peat JK: Evidence for the increase in asthma worldwide. Ciba Found Symp 1997;206:122-139.

$>2$ Worldwide variation in the prevalence of asthma symptoms: the International Study of Asthma and Allergies in Childhood (ISAAC). The International study of Asthma and Allergies in Childhood (ISAAC) steering committee. Eur Respir J 1998;12:315335.

3 Behbehani NA, Abal A, Syabbalo NC, AbdAzeem A, Shareef E, Al-Momen J: Prevalence of asthma, allergic rhinitis, and eczema in 13- to 14-year-old children in Kuwait: an ISAAC study. Ann Allergy Asthma Immunol 2000;85:58-63.

-4 Shaw R, Woodman K, Ayson M, Dibdin S, Winkelmann R, Crane J, Beasley R, Pearce $\mathrm{N}$ : Measuring the prevalence of bronchial hyper-responsiveness in children. Int J Epidemiol 1995;24:597-602.

5 European Community Respiratory Health Survey: Variations in the prevalence of respiratory symptoms, self-reported asthma attacks, and use of asthma medication in the European Community Respiratory Health Survey (ECRHS). Eur Respir J 1996;9:687695.

-6 Leung R, Wong G, Lau J, Ho A, Chan JK, Choy D, Douglass C, Lai CK: Prevalence of asthma and allergy in Hong Kong school children: an ISAAC study. Eur Respir J 1997; 10:354-360.
7 Anderson HR, Pottier AC, Strachan DP: Asthma from birth to age 23: incidence and relation to prior and concurrent atopic disease. Thorax 1992;47:537-542.

-8 Sears MR, Burrows B, Flannery EM, Herbison GP, Holdaway MD: Atopy in childhood. I. Gender and allergen-related risks for development of hay fever and asthma. Clin Exp Allergy 1993;23:941-948.

-9 Ezeamuzie CI, Al-Mousawi M, Dashti H, alBashir A, al-Hage M, al-Alis: Prevalence of allergic sensitization to inhalant allergens among blood donors in Kuwait - a desert country. Allergy 1997;52:1194-1200.

10 Mohamed DE, Haii MA, Al-Kazmi K: Descriptive Analysis of Asthma and Other Allergic Diseases in Kuwait. Monograph Ministry of Health Kuwait, 1983.

11 Ellul-Micallef R, Al-Ali S: The spectrum of bronchial asthma in Kuwait. Clin Allergy 1984:14:509-517.

12 Wilkinson WM: Development of allergy in the desert. J Trop Med Hyg 1964;67:16-18.

13 Al-Awadi AA: The Story of Allergy in Kuwait I: Prevalence and Role of Environmental Factors. Monograph Ministry of Health Kuwait, 1973.
14 Goren Al, Hellman S: Changing prevalence of asthma among school children in Israel. Eur Respir J 1997;10:2279-2284.

15 Pearce N, Weiland S, Keil U, Langridge P, Anderson HR, Strachan D, Bauman A, Young L, Gluyas P, Ruffin D: Self-reported prevalence of asthma symptoms in children in Australia, England, Germany and New Zealand: an international comparison using the ISAAC protocol. Eur Respir J 1993;6: 1455-1461.

16 U.S. interagency team proposes program to quantify effects of Kuwait oil fires. J Air Waste Manage Assoc 1991;41:852-853.

17 Madany IM, Raveendran E: Polycyclic aromatic hydrocarbons, nickel and vanadium in air particulate matter in Bahrain during the burning of oil fields in Kuwait. Sci Total Environ 1992;116:281-289.

18 Petruccelli BP, Goldenbaum M, Scott B, Lachiver R, Kanjarpane D, Elliott E, Francis M, McDiarmid MA, Deeter D: Health effects of the 1991 Kuwait oil fires: a survey of US army troops. J Occup Environ Med 1999;41: 433-439.

19 Lange JL, Schwartz DA, Doebbeling BN, Heller JM, Thorne PS: Exposures to the Kuwait oil fires and their association with asthma and bronchitis among gulf war veterans. Environ Health Perspect 2002;110:11411146. 
20 Wahn U, Lau S, Bergmann R, Kulig M, Foster J, Bergmann K, Bauer CP, GuggenmoosHolzmann I: Indoor allergen exposure is a risk factor for sensitization during the first three years of life. J Allergy Clin Immuno 1997;99:763-769.

-21 Munir AKM, Kjellman NM, Bjorksten B: Exposure to indoor allergens in early infancy and sensitization. J Allergy Clin Immuno 1997;100:177-181.

$\checkmark 22$ Peat JK: Can asthma be prevented? Evidence from epidemiological studies of children in Australia and New Zealand in the last decade. Clin Exp Allergy 1997;28:261-265.

$\checkmark 23$ Cursive A, Taggart SCO, Francis HC, Chapman MD, Woodcock A: Exposure to house dust mite allergens and the clinical activity of asthma. J Allergy Clin Immunol 1995;98: 64-72.

$>24$ Fleming DM, Crombie DL: Prevalence of asthma and hay fever in England and Wales. BMJ 1987;294:279-283.

25 Burney PGJ, Chinn S, Rona RJ: Has the prevalence of asthma increased in children? Evidence from the national study of health and growth 1973-1986. BMJ 1990;300:13061310.

-26 Burr ML, Butland BK, King S, Vaughan-Williams E: Changes in asthma prevalence: two surveys 15 years apart. Arch Dis Child 1989; 64:1452-1456.

-27 Ninan TK, Russel G: Respiratory symptoms and atopy in Aberdeen school children: evidence from two surveys 25 years apart. BMJ 1992;304:873-875.
28 Gergen PJ, Mullally DI, Evans R: National survey of prevalence of asthma among children in the United States, 1976 to 1980 . Pediatrics $1988 ; 81: 1-7$.

29 Peat JK, Van den Berg RH, Green WF, Mellis CM, Leeder SRl: Changing prevalence of asthma in Australian children. BMJ 1994; 308:1591-1596.

30 Shaw RA, Crane J, O’Donnell TV, Porteous LE, Coleman ED: Increasing asthma prevalence in a rural New Zealand adolescent pop ulation: 1975-89. Arch Dis Child 1990;65: 1319-1323.

-31 Zollner IK, Weiland SK, Piechotowski I, Gabria T, Von Mutius E: No increase in the prevalence of asthma, allergies, and atopic sensitization among children in Germany: 1992-2001. Thorax 2005;60:545-548.

32 Ronchetti R, Villa M, Barreto M, Rota R, Pagani J: Is the increase in childhood asthma coming to an end? Findings from three surveys in Rome, Italy. Eur Respir J 2001;17:881886.

33 Braun-Fahrländer C, Gassner M, Grize L, Takken-Sahli K, Neu U, et al: No further increase in asthma, hay fever and atopic sensitisation in adolescents living in Switzerland. Eur Respir J 2004;23:407-413.
34 Toelle BG, Ng K, Belousova E, Salome CM, Peat JK, Marks GB: Prevalence of asthma and allergy in schoolchildren in Belmont, Australia: three cross sectional surveys over 20 years. BMJ 2004;328:386-387.

35 Fleming DM, Sunderland R, Cross KW, Ross AM: Declining incidence of episodes of asthma: a study of trends in new episodes presenting to general practitioners in the period 1989-98. Thorax 2000;55:657-661.

36 Asher MI, Montefort S, Bjorksten B, Lai CK, Strachan DP, Weiland SK, Williams H: Worldwide time trends in the prevalence of symptoms of asthma, allergic rhinoconjunctivitis and eczema in childhood: ISSAC phases one and three repeat multicountry cross-sectional survey. Lancet 2006;368: 733-743.

37 Maziak W, Behrens T, Brasky T, Duhme H, Rzehak P: Are asthma and allergies in children and adolescents increasing? Results from ISAAC phase I and phase III surveys in Munster, Germany. Allergy 2003;58:572579.

38 Anderson HR, Ruggles R, Strachan DP, Austin JB, Burr M: Trends in prevalence of symptoms of asthma, hay fever, and eczema in 12-14 year olds in the British Isles, 19952002: questionnaire survey. BMJ 2004;328: 1052-1053.

-39 Custovic A, Simpson A: Environmental allergens exposure, sensitization and asthma: from whole populations to individuals at risk. Thorax 2004;59:825-827. 